\title{
Effect of lignin content on changes occurring in poplar cellulose ultrastructure during dilute acid pretreatment
}

Qining Sun ${ }^{1}$, Marcus Foston ${ }^{2}$, Xianzhi Meng ${ }^{1}$, Daisuke Sawada ${ }^{3}$, Sai Venkatesh Pingali ${ }^{3}$, Hugh M O'Neill', Hongjia Li $i^{4}$, Charles E Wyman ${ }^{4,5,6}$, Paul Langan ${ }^{3}$, Art J Ragauskas ${ }^{1,6,7^{*}}$ and Rajeev Kumar ${ }^{4,6}$

\begin{abstract}
Background: Obtaining a better understanding of the complex mechanisms occurring during lignocellulosic deconstruction is critical to the continued growth of renewable biofuel production. A key step in bioethanol production is thermochemical pretreatment to reduce plant cell wall recalcitrance for downstream processes. Previous studies of dilute acid pretreatment (DAP) have shown significant changes in cellulose ultrastructure that occur during pretreatment, but there is still a substantial knowledge gap with respect to the influence of lignin on these cellulose ultrastructural changes. This study was designed to assess how the presence of lignin influences DAP-induced changes in cellulose ultrastructure, which might ultimately have large implications with respect to enzymatic deconstruction efforts.
\end{abstract}

Results: Native, untreated hybrid poplar (Populus trichocarpa $\times$ Populus deltoids) samples and a partially delignified poplar sample (facilitated by acidic sodium chlorite pulping) were separately pretreated with dilute sulfuric acid $(0.10 \mathrm{M})$ at $160^{\circ} \mathrm{C}$ for 15 minutes and 35 minutes, respectively. Following extensive characterization, the partially delignified biomass displayed more significant changes in cellulose ultrastructure following DAP than the native untreated biomass. With respect to the native untreated poplar, delignified poplar after DAP (in which approximately $40 \%$ lignin removal occurred) experienced: increased cellulose accessibility indicated by increased Simons' stain (orange dye) adsorption from 21.8 to $72.5 \mathrm{mg} / \mathrm{g}$, decreased cellulose weight-average degree of polymerization $\left(\mathrm{DP}_{\mathrm{w}}\right)$ from 3087 to 294 units, and increased cellulose crystallite size from 2.9 to $4.2 \mathrm{~nm}$. These changes following DAP ultimately increased enzymatic sugar yield from 10 to $80 \%$.

Conclusions: Overall, the results indicate a strong influence of lignin content on cellulose ultrastructural changes occurring during DAP. With the reduction of lignin content during DAP, the enlargement of cellulose microfibril dimensions and crystallite size becomes more apparent. Further, this enlargement of cellulose microfibril dimensions is attributed to specific processes, including the co-crystallization of crystalline cellulose driven by irreversible inter-chain hydrogen bonding (similar to hornification) and/or cellulose annealing that converts amorphous cellulose to paracrystalline and crystalline cellulose. Essentially, lignin acts as a barrier to prevent cellulose crystallinity increase and cellulose fibril coalescence during DAP.

Keywords: Cellulose ultrastructure, Lignin content, Dilute acid pretreatment, Delignification, Enzymatic sugar release, Biomass recalcitrance

\footnotetext{
* Correspondence: aragausk@utk.edu

'School of Chemistry and Biochemistry, Renewable Bioproducts Institute,

Georgia Institute of Technology, 500 10th Street, N.W. Atlanta, GA

30332-0620, USA

${ }^{6}$ BioEnergy Science Center (BESC), Oak Ridge National Laboratory (ORNL),

Oak Ridge, TN, 37831, USA

Full list of author information is available at the end of the article
}

\section{Biomed Central}

(c) 2014 Sun et al.; licensee BioMed Central Ltd. This is an Open Access article distributed under the terms of the Creative Commons Attribution License (http://creativecommons.org/licenses/by/4.0), which permits unrestricted use, distribution, and reproduction in any medium, provided the original work is properly credited. The Creative Commons Public Domain Dedication waiver (http://creativecommons.org/publicdomain/zero/1.0/) applies to the data made available in this article, unless otherwise stated. 


\section{Background}

Grass and woody biomass is mainly composed of three biopolymers, namely cellulose, hemicelluloses, and lignin, which are largely located in secondary cell walls [1]. Cellulose (typically 40 to $50 \mathrm{wt} \%$ of the cell wall) is a linear polysaccharide that consists of repeating $\beta$-1,4-glycosidic units and that forms both crystalline and amorphous morphologies. These cellulosic morphologies are the basis for a framework of microfibrils further associated into bundles through strong intermolecular hydrogen bonds [2]. Hemicellulose (typically 15 to 25 wt.\% of the cell wall), another polysaccharide, is typically a shorter and highly branched heteropolymer composed of both 5- and 6carbon monomeric sugars [3]. Lignin (typically 10 to $30 \mathrm{wt} . \%$ of the cell wall) is derived from hydroxycinnamyl monomers with various degrees of methoxylation forming a racemic, cross-linked, and highly heterogeneous aromatic macromolecule. Lignin and hemicellulose is embedded between and around cellulose microfibrils, providing rigidity and structural support to the plant cell wall [4]. Lignin, considered as the essential 'glue' holding cellulose and hemicellulose together, is one of the most recalcitrant components of the major plant cell wall biopolymer. The plant cell wall is described as existing as a multicomponent structure that is hierarchical, with order existing on multiple length-scales. This multi-component structure forms an encapsulating matrix of lignin and hemicellulose, confining cellulose and restricting the bioavailability of cellulose for biofuels generation [5]. Also, covalent cross-linking between carbohydrates and lignin, known as lignin carbohydrate complexes (LCCs), could act as additional sites confining cellulose and promoting cell wall recalcitrance [6,7].

The biochemical conversion of biomass to biofuels involves three essential steps: pretreatment to reduce the inherent plant cell wall recalcitrance, enzymatic hydrolysis to deconstruct polysaccharides into fermentable sugars, and fermentation to convert those sugars into ethanol [8]. The main challenges related to large-scale biochemical conversion involve considerable cost and inefficiency related to enzymatic deconstruction of polysaccharides embedded in the complex structure of the plant cell wall [9], which were designed over millions of years of evolution to resist enzymatic and chemical attack. As a result, effective enzymatic hydrolysis is closely related to plant cell wall physiochemical features including cell wall chemistry and composition, cellulose ultrastructure, enzymatic accessible surface area, and so forth [10-13].

In particular, the literature has consistently cited cellulose ultrastructure, mainly crystallinity index (CrI) and degree of polymerization (DP), as a relevant performance indicator of enzymatic hydrolysis [14]. However, the exact role of cellulose CrI and DP on enzymatic hydrolysis is still not clearly defined due to the fact that biomass recalcitrance is a complex, multi-variant or scale phenomenon. For example, Del Rio et al. in a study on the enzymatic hydrolysis of organosolv-pretreated softwood materials demonstrated single substrate characteristics such as fiber length, cellulose DP, and cellulose $\mathrm{CrI}$ have little effect on an enzymatic hydrolysis yield or rate [15]. However, a variety of studies show low cellulose CrI substrates have high enzymatic digestibility; one in particular by Hall et al. demonstrated this on microcrystalline cellulose [16]. However, a study by Foston and Ragauskas seems to indicate that despite increases in cellulose CrI, dilute acid pretreated poplar and switchgrass showed highly increased enzymatic yields [17]. Despite these differing conclusions on the effect of cellulose ultrastructure, it is quite clear that cellulose CrI and DP are altered during pretreatment and can affect biomass recalcitrance [14,18].

The goal of pretreatment is therefore to modify plant cell wall physiochemical features such that the resulting biomass is more amenable to enzymatic deconstruction. The major effect of dilute acid pretreatment (DAP) on lignocellulose is the hydrolysis of hemicellulose and redistribution of lignin which, on average, causes beneficial (to enzymatic deconstruction) changes in cell wall chemistry and composition as well as enzymatic accessible surface area. $[19,20]$ DAP. However, it also causes changes in cellulose ultrastructure, which most likely are deleterious (to enzymatic deconstruction) including: increases in the relative cellulose $I_{\beta}$ and paracrystalline content, increases in cellulose $\mathrm{CrI}$, and increases in cellulose crystallite dimension [17]. The increase in relative cellulose $I_{\beta}$ content during DAP is accompanied by a decrease in relative cellulose $I_{\alpha}$ content, which has been attributed to a thermal transformation of the cellulose $\mathrm{I}_{\alpha}$ allomorph $[17,21]$. Cellulose $\mathrm{I}_{\alpha}$ has a meta-stable triclinic one-chain crystal structure, whereas cellulose $I_{\beta}$ has a monoclinic two-chain crystal structure and is the more thermodynamic-favored crystal structure generated upon annealing at high temperatures [22-25]. DAP also produces characteristic increases in the content of paracrystalline cellulose and simultaneous decreases in the relative proportion of amorphous cellulose. The above phenomena in conjunction with decreases that occur in cellulose DP during DAP (until a 'level-off' DP is reached) suggest that preferential degradation or removal of amorphous cellulose, and/or a hydrothermal annealing-like process, orders amorphous cellulose and expands cellulose crystallite dimensions [26]. Nuclear magnetic resonance (NMR) spectroscopy [17] and X-ray diffraction (XRD) $[27,28]$ results also show increases in cellulose crystallite dimension with DAP, which has been attributed to an irreversible process of cellulose co-crystallization and described as similar to hornification. In both cases, changes occurring in cellulose ultrastructure upon pretreatment 
require elevated temperatures and seem to be related to overcoming a kinetic barrier.

Lignin can act as a physical barrier, encapsulating and confining cellulose. This impacts enzymatic digestibility negatively $[29,30]$. However, if hydrothermal annealing of cellulose or cellulose co-crystallization processes are the major drivers for deleterious change in cellulose ultrastructure, the presence of lignin during pretreatment could retard those changes from occurring. This suggests, in the absence of an intact hemicelluloses and lignin matrix at pretreatment (elevated hydrothermal) conditions, that: removal of the lignin barrier layers causes cellulose crystallites to have an increased propensity to co-crystallize and coalesce through irreversible hydrogen bonding; removal of the lignin barrier layers and lack of spatial confinement causes cellulose crystallites to have an increased propensity to expand through cellulose annealing and conversion of amorphous to crystalline cellulose; and/or removal of the lignin protecting layers causes the pretreatment severity experienced by the cellulose to be higher, not altering, but simply increasing the effect of pretreatment on cellulose ultrastructure. In combination with previous studies about the complete delignification resulting in the lower sugar release [30], this finding could have significant implications, for example, on how genetically modified low-lignin plants are pretreated for enzymatic hydrolysis. Also, establishing a correlation between lignin content and the changes that occur in cellulose ultrastructure during pretreatment could help elucidate the mechanisms that are responsible for cellulose CrI and crystallite size increase during DAP. In order to investigate the effect of lignin content within the presence of an intact lignin-carbohydrate complex has on changes occurring to cellulose ultrastructure during DAP, and consequently enzymatic hydrolysis, Populus trichocarpa x Populus deltoides substrates with controlled lignin contents were prepared and then pretreated.

\section{Results and discussion}

In an effort to assess potential cell wall compositional and chemistry changes occurring during delignification and DAP, especially those associated with biomass degradation and consequently to changes in enzymatic hydrolysis, cell wall compositional analysis was conducted.

\section{Cell wall compositional analysis}

Carbohydrate and Klason lignin (K-lignin) content for the untreated, delignified, and dilute acid pretreated poplar solids are reported in Figure 1. DAP as a costeffective pretreatment method that significantly reduces lignocellulosic recalcitrance by removing hemicellulose, disrupting lignin-hemicellulose matrix, and redistributing lignin [17]. Delignification (holocellulose pulping) of the native poplar with starting K-lignin of about $23 \mathrm{wt} \%$ (Table 1 PL23-t0; $t$ indicates DAP time in minutes) for 15 minutes resulted in a K-lignin content of about $19 \mathrm{wt}$ $\%$ (PL19-t0 sample) and increased the relative glucan and xylan contents in the residual solid from 49 to $56 \%$ and 22 to $23 \%$, respectively. Further, delignification for an additional 15 minutes dropped lignin content to about 14 wt\% (to produce the PL14-t0 sample), however, there was little change in the relative glucan and xylan contents. Based solely on this data, it seems reasonable to suggest that limited delignification had little effect on the cell wall carbohydrate components.

When native poplar sample (PL23-t0) was subjected to DAP for 15 minutes (to produce sample PL23-t15), there was a significant reduction of xylan from 21 to $1 \%$ (PL23-t15), with a corresponding increase of the relative glucan and Klason lignin contents. When the residence time of DAP was extended to 35 minutes, the residual solids had a slightly lower relative glucan and higher relative lignin content than the solids collected after 15minutes pretreatment. This could be a result of hydrolytic degradation of cellulose but also, in part, result

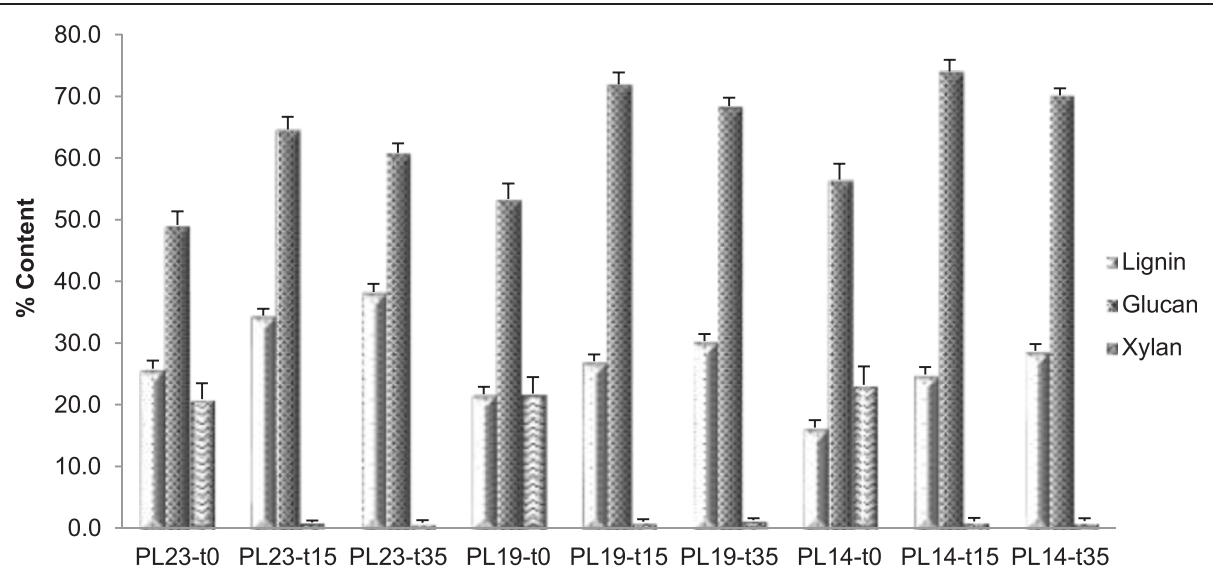

Figure 1 Klason lignin, glucan, and xylan contents from dilute acid pretreated poplar with reduced lignin contents. Sample code with definition is in Table 1. 
Table 1 Pretreatment methods and conditions of poplar

\begin{tabular}{|c|c|c|c|}
\hline Sample code & Poplar sample & Starting \% Klason lignin & Pretreatment conditions \\
\hline PL23-t0 & Native & 23.2 & - \\
\hline PL23-t15 & Dilute acid pretreated & 23.2 & $0.1 \mathrm{M} \mathrm{H}_{2} \mathrm{SO}_{4}, 160^{\circ} \mathrm{C}, 15$ minutes \\
\hline PL23-t35 & Dilute acid pretreated & 23.2 & $0.1 \mathrm{M} \mathrm{H}_{2} \mathrm{SO}_{4}, 160^{\circ} \mathrm{C}, 35$ minutes \\
\hline PL19-t0 & Delignified & 19.2 & - \\
\hline PL19-t15 & Delignified then dilute acid pretreated & 19.2 & $0.1 \mathrm{M} \mathrm{H}_{2} \mathrm{SO}_{4}, 160^{\circ} \mathrm{C}, 15$ minutes \\
\hline PL19-t35 & Delignified then dilute acid pretreated & 19.2 & $0.1 \mathrm{M} \mathrm{H}_{2} \mathrm{SO}_{4}, 160^{\circ} \mathrm{C}, 35$ minutes \\
\hline PL14-t0 & Delignified & 14.3 & - \\
\hline PL14-t15 & Delignified then dilute acid pretreated & 14.3 & $0.1 \mathrm{M} \mathrm{H}_{2} \mathrm{SO}_{4}, 160^{\circ} \mathrm{C}, 15$ minutes \\
\hline PL14-t35 & Delignified then dilute acid pretreated & 14.3 & $0.1 \mathrm{M} \mathrm{H}_{2} \mathrm{SO}_{4}, 160^{\circ} \mathrm{C}, 35$ minutes \\
\hline
\end{tabular}

from the re-polymerization of polysaccharide degradation products forming pseudo-lignin [31]. Delignification of poplar followed by DAP resulted in a similar initial increase in relative glucan and Klason lignin contents, but a slight decrease in relative glucan content with increasing DAP residence time. Though delignification to a greater extent, followed by DAP, seems to correspond with greater magnitudes of change.

\section{Fourier transform infrared (FTIR) spectroscopy analysis}

Relative changes in cell wall chemistry can be extracted from various absorption bands and presented in Table 2. The normalized Fourier transform infrared (FTIR) absorption spectra of lignocellulose at a band position of $1,424 \mathrm{~cm}^{-1}$ is primary due to the presence of cellulose, specifically the $\mathrm{CH}_{2}$ scissor motion of cellulose [32-34]. A decrease in the spectral band at $1,424 \mathrm{~cm}^{-1}$, as well as other cellulose specific spectral bands, can be used to determine possible degradation isolated to cellulose during sodium chlorite delignification followed by pretreatment. An increase in spectral intensity at $3,340 \mathrm{~cm}^{-1}$ represented an increase in cellulose-hydrogen bonding and indicated possible co-crystallization. Spectral intensity at 2,900 and 1,367 $\mathrm{cm}^{-1}$ was attributed to C-Hbond stretching and relative decreases in those bands suggested general degradation to the biomass was occurring based on the removal of methyl and methylene groups. After DAP the reduction in the band intensity from around $1,740 \mathrm{~cm}^{-1}$ representing carbonyl groups associated with lignin [35], typically indicated possible cleavage

Table 2 Relative changes in poplar samples after dilute acid pretreatment by Fourier transform infrared spectroscopy

\begin{tabular}{|c|c|c|c|c|c|c|c|c|c|c|}
\hline \multirow{2}{*}{$\begin{array}{l}\text { Band } \\
\text { position }\end{array}$} & \multirow{2}{*}{ Assignment [32-38] } & \multicolumn{9}{|c|}{ Pretreatment conditions } \\
\hline & & PL23-t0 & PL23-t15 & PL23-t35 & PL19-t0 & PL19-t15 & PL19-t35 & PL14-to & PL14-t15 & PL14-t35 \\
\hline 3340 & $\begin{array}{l}\text { O-H stretching, related to } \\
\text { cellulose-hydrogen bonds }\end{array}$ & 1.7 & 1.6 & 1.5 & 2.1 & 1.9 & 2.2 & 2.1 & 1.8 & 2.3 \\
\hline 2900 & $\begin{array}{l}\mathrm{C}-\mathrm{H} \text { stretching, related to biomass } \\
\text { methyl/methylene group }\end{array}$ & 0.8 & 0.8 & 0.9 & 0.9 & 0.8 & 1.0 & 0.9 & 0.8 & 1.1 \\
\hline 1740 & $\begin{array}{l}\text { Carbonyl bonds ascribed to } \\
\text { hemicelluloses }\end{array}$ & 1.3 & - & - & 1.6 & - & - & 1.5 & - & - \\
\hline 1595 & Lignin aromatic ring stretch & 0.7 & 0.8 & 0.8 & 0.6 & 0.7 & 0.7 & 0.5 & 0.5 & 0.7 \\
\hline 1510 & Lignin aromatic ring stretch & 0.6 & 0.9 & 1.0 & 0.5 & 0.8 & 0.8 & 0.4 & 0.7 & 0.7 \\
\hline 1424 & $\mathrm{CH}_{2}$ scissor motion in cellulose & 1.0 & 1.0 & 1.0 & 1.0 & 1.0 & 1.0 & 1.0 & 1.0 & 1.0 \\
\hline 1367 & Aliphatic $\mathrm{C}-\mathrm{H}$ stretch in $\mathrm{CH}_{3}$ & 1.1 & 0.9 & 0.8 & 1.3 & 1.1 & 1.1 & 1.4 & 1.2 & 1.1 \\
\hline 1265 & $\begin{array}{l}\text { Ester absorption associated with } \\
\text { uronic acid }\end{array}$ & - & 1.1 & 1.2 & - & 1.2 & 1.1 & - & 1.3 & 1.2 \\
\hline 1240 & $\begin{array}{l}\text { C-O absorption from acetyl group } \\
\text { cleavage }\end{array}$ & 1.6 & 1.3 & 1.2 & 2.2 & 1.1 & 1.0 & 2.0 & 1.2 & 1.1 \\
\hline 1059 & C-O stretch in secondary alcohol & 5.0 & 3.6 & 3.4 & - & 4.0 & 4.3 & - & 5.3 & 4.9 \\
\hline $1100 / 900$ & $\begin{array}{l}\text { Crystalline to amorphous cellulose } \\
\text { ration }\end{array}$ & 3.0 & 4.4 & 4.5 & 2.9 & 3.7 & 4.5 & 2.7 & 4.1 & 4.4 \\
\hline $750 / 710$ & $\mathrm{I}_{\alpha} / \mathrm{I}_{\beta}$ & 0.9 & 0.6 & 0.4 & 0.3 & 0.3 & 0.2 & 0.3 & 0.3 & 0.2 \\
\hline 900 & Amorphous cellulose & 1.1 & 0.6 & 0.6 & 1.2 & 0.8 & 0.8 & 1.2 & 0.9 & 0.7 \\
\hline
\end{tabular}

Sample code with definition is in Table 1. 
of association of polysaccharide with lignin and the removal of acetylated hemicellulose. The presence of acetyl groups have long be thought to inhibit enzymatic hydrolysis, and the de-acetylation that occurred during DAP suggested hemicelluloses hydrolysis that would facilitate the cellulose hydrolysis to sugar conversion $[36,37]$. In all substrates after DAP, spectral intensity increased at 1,595 and $1,510 \mathrm{~cm}^{-1}$ representing aromatic rings $[34,38]$, indicated the increase in Klason lignin content after DAP. The reduction of spectral intensity at $1,240 \mathrm{~cm}^{-1}$ in all pretreated samples was tentatively attributed to the cleavage of acetyl groups. In addition, FTIR semi-quantitative analysis can examine the relative structural change in cellulose crystalline and amorphous components. The reduction of ratio $I_{\alpha} / I_{\beta}$ suggested the reduction of $\mathrm{I}_{\alpha}$ and/or the increase of $\mathrm{I}_{\beta}$, and/or cellulose crystalline allomorph transformation from $\mathrm{I}_{\alpha}$ to $\mathrm{I}_{\beta}$. The increase of ratio $1,100 / 900 \mathrm{~cm}^{-1}$ plus a reduction in $900 \mathrm{~cm}^{-1}$ suggested that the cellulose amorphous components were degraded to some extent and that amorphous cellulose could be transformed into crystalline cellulose.

\section{Cellulose degree of polymerization}

The cellulose average DP was determined following virtually complete lignin and hemicellulose removal and then using a published gel permeation chromatography (GPC) procedure [17]. The cellulose DP results were used to determine the ratio of terminal to interior $\beta$ glucosidic bonds that can be effectively used to analyze the relative change in cellulose chain length. Figure 2 shows the effect delignification and DAP had on poplar cellulose number-average DP $\left(\mathrm{DP}_{\mathrm{n}}\right)$ and weight-average $\mathrm{DP}\left(\mathrm{DP}_{\mathrm{w}}\right)$. Delignification alone had a very limited effect on either $\mathrm{DP}_{\mathrm{n}}$ or $\mathrm{DP}_{\mathrm{w}}$, displaying at most a $5 \%$ reduction. This result is in good agreement with a previous study analyzing the effect of holocellulose pulping on cellulose molecular weight. [39] However, DAP caused dramatic reductions in cellulose DP with increased residence time. The fact that a large portion of the cellulosic component had been hydrolytically degraded during DAP could have had large implication on concurrent changes in cellulose ultrastructure, specifically the change of cellulose crystallinity. However, significant differences between cellulose DP for the sample that was subjected to DAP only and samples that was delignified with sodium chlorite followed by DAP were not detected. This is most likely a result of the cellulose reaching its leveling-off DP [17].

\section{Cellulose ultrastructure and crystallinity by nuclear magnetic resonance spectroscopy}

In an effort to better understand the detailed ultrastructural changes occurring within cellulose during partial delignification followed by DAP, ${ }^{13} \mathrm{C}$ cross-polarization (CP) magic-angle spinning (MAS) NMR spectroscopy experiments were applied to isolated cellulose to determine the relative intensity of crystalline and amorphous ultrastructural components of cellulose, following published procedures $[40,41]$. These results were then used to support observations made via FTIR analysis and to understand how crystalline and amorphous ultrastructural components of cellulose vary as a result of DAP and delignification followed by DAP.

Cellulose\% crystallinity or CrI was obtained via twopeak integration of the ${ }^{13} \mathrm{C} \mathrm{CP} / \mathrm{MAS}$ spectrum of isolated cellulose. Cellulose $\mathrm{CrI}$ was calculated by taking the ratio of the integral of the cellulose $\mathrm{C}_{4}$-crystalline carbon region ( $\delta$ approximate to 85 to $92 \mathrm{ppm}$ ) over the integral of whole cellulose $\mathrm{C}_{4}$-carbon region ( $\delta$ approximate to 80 to $92 \mathrm{ppm}$ ), and the results are shown in Figure 3. Delignification alone had little effect on cellulose CrI, in contrast, DAP generated an increase from 57 to $65 \%$, approximately. Extended DAP residence time caused a further

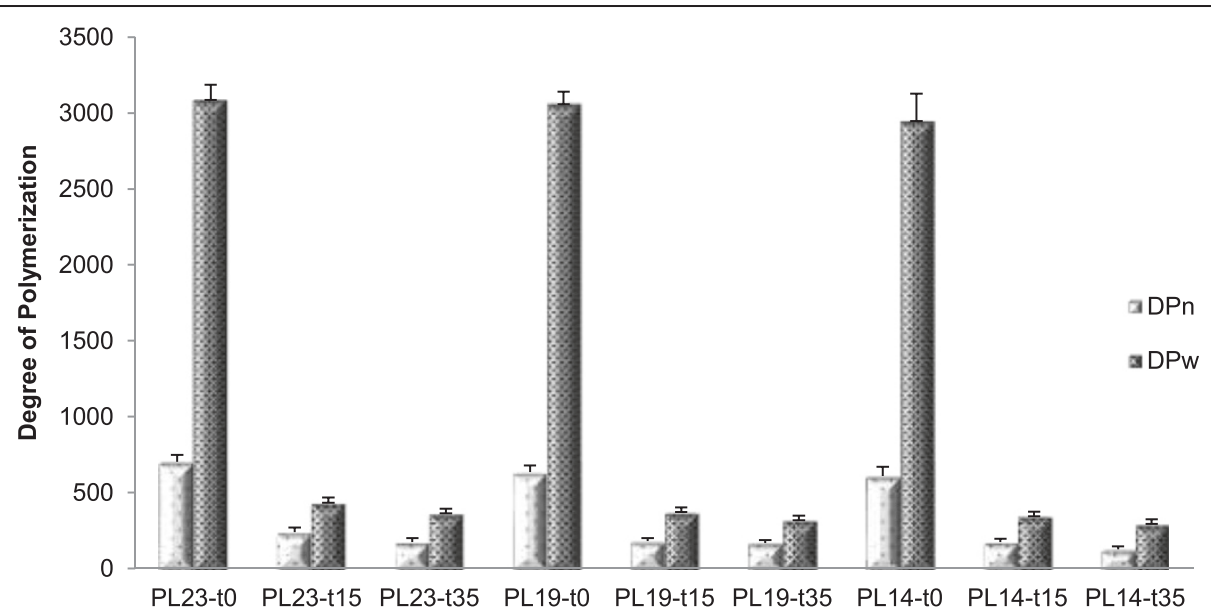

Figure 2 Average number and weight degree of polymerization of cellulose. $\mathrm{DP}_{\mathrm{n}}$ : number-average degree of polymerization $\mathrm{DP}_{\mathrm{w}}$ : weightaverage degree of polymerization. Sample code with definition is in Table 1. 


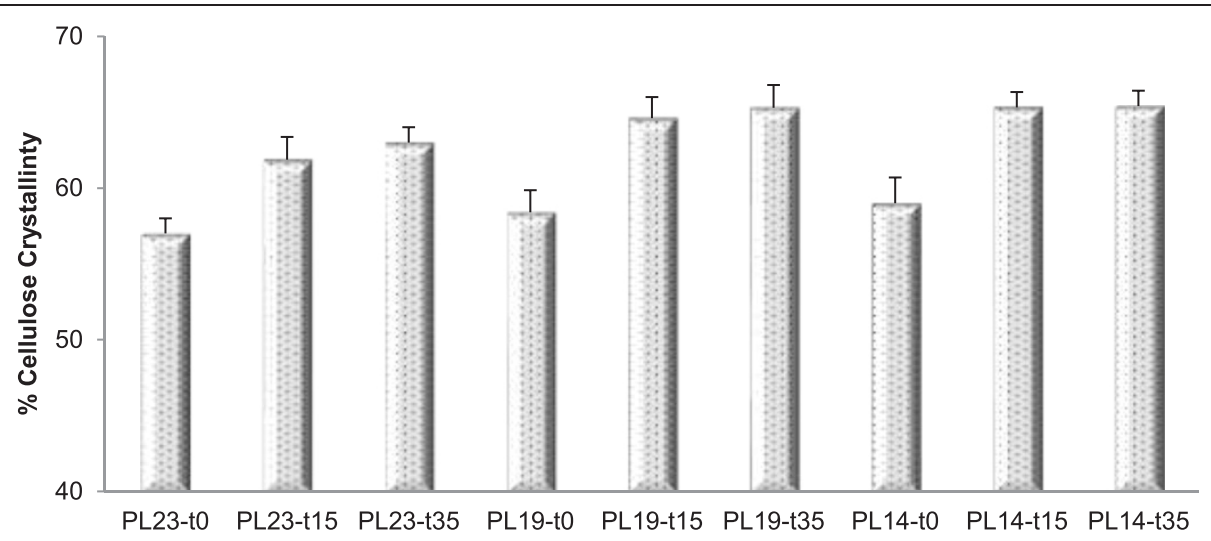

Figure 3 Percent crystallinity of cellulose from dilute acid pretreated poplar with reduced lignin contents. Sample code with definition is in Table 1.

increase in the cellulose crystallinity, and this trend continued for samples that were subjected to delignification followed by DAP. This increase in cellulose CrI with pretreatment, in part, resulted from the preferential hydrolysis and removal of amorphous cellulose, an inference supported by the FTIR results and cellulose DP data.

The relative proportion of cellulose crystalline allomorphs, including $\mathrm{I}_{\alpha}, \mathrm{I}_{\beta}$, and paracrystalline and amorphous cellulose at accessible and inaccessible fibril surfaces can also be extracted from the same $\mathrm{C}_{4}$-carbon region in the ${ }^{13} \mathrm{C}$ CP/MAS spectrum of isolated cellulose using a more complex seven-peak model and a least-squared non-linear fit. The results of this analysis are shown in Figure 4. Delignification seems not to have a significant effect on cellulose ultrastructure for both crystalline and amorphous components, which is in good agreement with a previous study analyzing the effect of acidified sodium chlorite treatment on pure cellulose [30]. However, DAP caused an observed increase in relative cellulose $\mathrm{I}_{\beta}$ content, which was accompanied by a reduction in resonances representing cellulose $I_{\alpha+\beta}$ and $I_{\alpha}$ content, suggesting cellulose $I_{\alpha}$ was subject to preferential degradation and/or transformation into cellulose $\mathrm{I}_{\beta}$ during hydrothermal conditions. The latter would occur via $\mathrm{H}$-bonding disruption and rearrangement under pretreatment conditions. This could be regarded as a cellulose annealing [42]. Paracrystalline cellulose is a form of cellulose that is less ordered than crystalline cellulose but more ordered than amorphous cellulose, and has been proposed to exist on the sub-surface of crystallites as a thin molecular layer [43]. Further ordering of amorphous cellulose into these paracrystalline layers could contribute to the observed increase in $\mathrm{CrI}$ and expansion of the crystalline lattice. All pretreated samples had a higher relative intensity for paracrystalline than the native or solely delignified samples.

Two forms of non-crystalline cellulose have been identified within the $\mathrm{C}_{4}$-carbon region in a ${ }^{13} \mathrm{C} \mathrm{CP} / \mathrm{MAS}$ spectrum of isolated cellulose, amorphous cellulose at

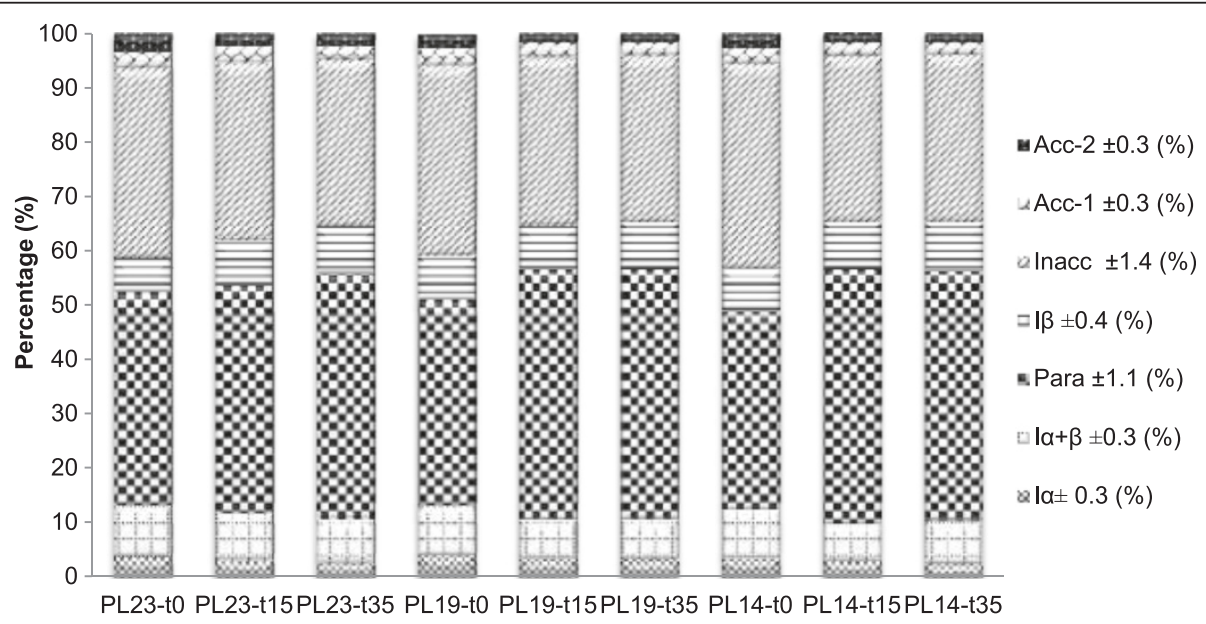

Figure 4 The relative\% cellulose crystalline allomorphs, paracrystalline cellulose and cellulose fibril surface. Para: paracrystalline cellulose; Inacc: Inaccessible fibril surface; Acc-1, Acc-2: Accessible fibril surface 1 and 2. Sample code with definition is in Table 1. 
accessible and inaccessible (fibril-to-fibril contact) fibril surfaces. The relative proportion of cellulose at accessible and inaccessible fibril surfaces is also shown in Figure 4. Delignification did not alter the inaccessible fibril surfaces but slightly decreased accessible surfaces, however, DAP generated obvious reduction in inaccessible and accessible surfaces. In conjunction with GPC and crystallinity results, it could suggest hydrolysis and degradation of amorphous cellulose is kinetically favored over that of crystalline cellulose during DAP, longer residence time could cause cellulose recrystallization into crystalline $I_{\beta}$, which proceeds with induced hydrogen bonding process in solvent of high polarity acidic system.

In addition to the relative proportion of cellulose crystalline allomorphs and amorphous cellulose at accessible and inaccessible fibril surfaces, the $\mathrm{C}_{4}$-carbon region in a ${ }^{13} \mathrm{C} \mathrm{CP} / \mathrm{MAS}$ spectrum of isolated cellulose along with a simple geometric cellulose fibril model $[44,45]$ can estimate the average lateral fibril dimension (LFD) and lateral fibril aggregate dimension (LFAD) of cellulose. The results of this analysis are shown in Figure 5. Delignification had little effect on LFD but generated an increase in LFAD from approximately 35 to $39 \mathrm{~nm}$, which could be attributed to lignin removal $[46,47]$. DAP seems to cause an increase in LFD and LFAD, where the extent of increase was directly correlated to the increase in pretreatment residence time. The effect of DAP on the increase of LFD and LFAD was further enhanced by greater delignification.

\section{Cellulose crystallite size analysis}

Wide-angle X-ray diffraction (WAXD), a more traditional but also complementary technique to NMR spectroscopy to extract information detailing cellulose ultrastructural features, is particularly sensitive to crystalline region due to their regular or repetitive arrangement of atoms. Two important measureable parameters are $\mathrm{d}_{h k l}$, distance between atomic planes perpendicular to $(h k l)$ direction and $\mathrm{L}_{h k l}$, the distance or size of crystalline order in the $(h k l)$ direction. As shown in Figure 6, delignification, DAP and delignification followed by DAP increased cellulose crystallite size to different extents. The increasing trend of cellulose crystallite size was in good qualitative agreement with the cellulose fibril dimensions extracted from NMR spectroscopy in Figure 5. DAP increased cellulose crystallite size of delignified substrates from 3.0 to $3.1 \mathrm{~nm}$ to 4.0 to $4.2 \mathrm{~nm}$, which is interesting because scattering studies of sliced intact poplar samples indicate the cellulose fibril-fibril distance is approximately $4.0 \mathrm{~nm}$ [27], and any increase in the crystallite size beyond $4.0 \mathrm{~nm}$ implies neighboring microfibrils coalesce by expelling any interstitial biopolymer or solvent. Cellulose microfibril coalescence would be mainly reflected in a decrease of accessible cellulose surfaces, enlargement of LFADs, and the increase of cellulose\% crystallinity. Moreover, the increase in the FTIR absorption bands ester linkages of covalent lactone bridges through esterification process could relate to occurred hornification [27], and the change of hydrogen-bonded hydroxyl group in poplar samples subjected to severely delignification followed by DAP also supports the cellulose crystallites growth via cocrystallize and coalesce.

\section{Simons' stain}

The changes of cellulose accessibility to cellulase caused by DAP and delignification followed by DAP were also evaluated to further study lignin impact on the accessible surface area of cellulose for downstream enzymatic hydrolysis. Simons' stain testing has been used to evaluate the accessibility of a lignocellulosic substrate by applying two dyes: Direct Blue (DB) 1 and Direct Orange (DO) 15 [48]. DB 1 has a well-defined chemical formula with a molecular diameter of approximately $1 \mathrm{~nm}$, whereas DO 15 is a poly-condensation product of 5nito-o-toluenesulfonic acid with a molecular diameter in the range of approximately 5 to $36 \mathrm{~nm}$. These two dyes

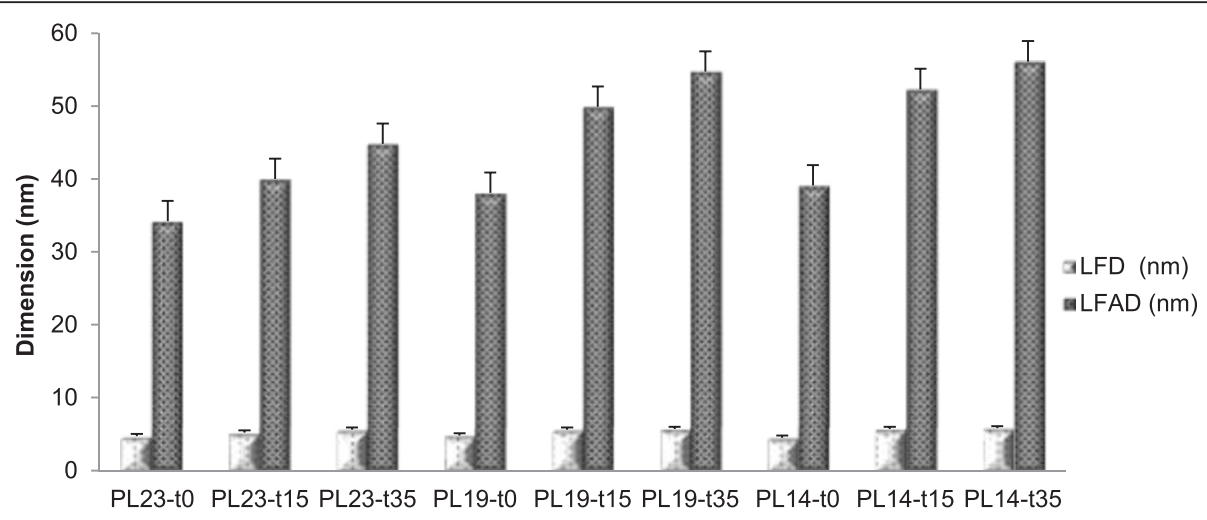

Figure 5 Lateral fibril dimension (LFD) and lateral fibril aggregate dimension (LFAD) of treated poplar cellulose. Sample code with definition is in Table 1. 


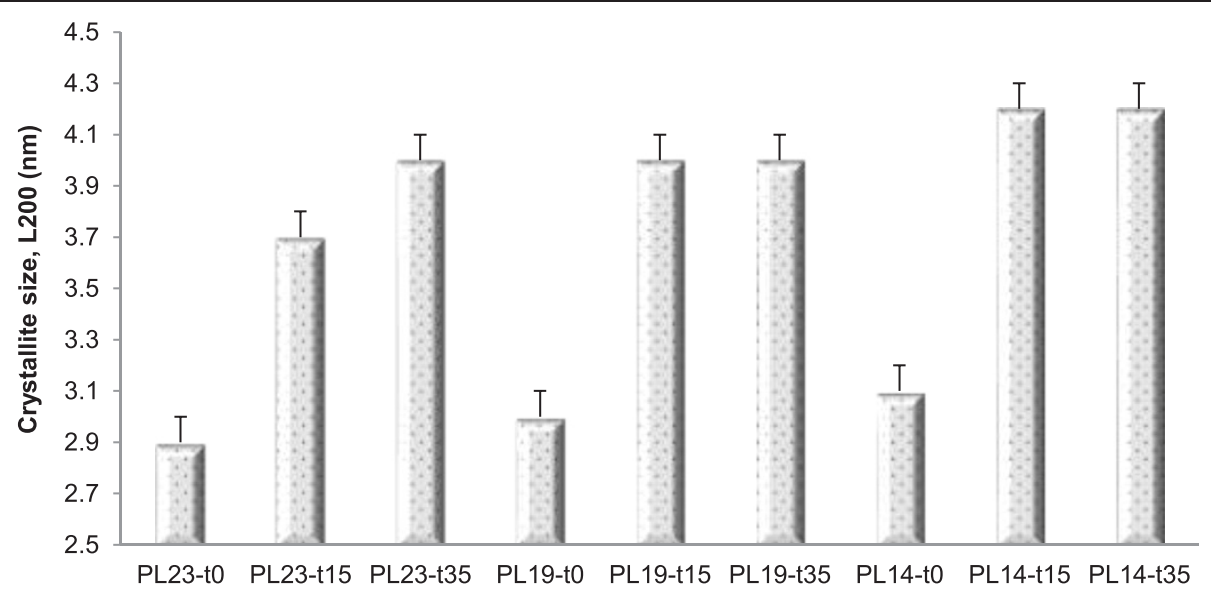

Figure 6 Crystallite size (L200) for treated poplar samples. Sample code with definition is in Table 1.

absorb different wavelengths of light, have different molecular sizes, and most importantly, have different binding affinities for cellulosic surfaces. Therefore, the ratio of DO 15 and DB 1 dye (O/B) adsorbed into the biomass can be used to indicate the relative accessibility of cellulose in a lignocellulosic substrate. Arantes and Saddler [49] found that the higher the O/B ratio, the lower the protein loading required for efficient hydrolysis. However, it is also necessary to analyze the maximum amount of DO 15adsorbed especially when large amounts of the smaller DB 1 dye are adsorbed by a substrate and cause a decrease in the overall $\mathrm{O} / \mathrm{B}$ ratio. In this case, there may be a significant amount of large pore and cellulose accessibility, but analysis based solely on the low $\mathrm{O} / \mathrm{B}$ ratio may skew the data interpretation [19].

As shown in Figure 7, the DO 15 adsorptions for samples which had not been subjected to DAP (PL23-t0,
PL19-t0, and PL14-t0) were 21.8, 23.1, and $29.7 \mathrm{mg} / \mathrm{g}$. This increase in DO 15 adsorption suggests delignification increases cellulose accessibility to some extent. For all samples under DAP for 35-minutes residence time, significant increases in the amount of DO 15 adsorbed were observed. The PL23-t0, PL19-t0, and PL14-t0 samples displayed an increase from 21.8 to $68.5 \mathrm{mg} / \mathrm{g}$, 23.1 to $70.4 \mathrm{mg} / \mathrm{g}$, and 28.7 to $72.5 \mathrm{mg} / \mathrm{g}$, respectively after DAP for 35 minutes. This result indicated that DAP significantly increased cellulose accessibility such that appreciable amounts of enzymes could have access to cellulose in spite of the fact that DAP actually increases the Klason lignin content. This suggested the increased cellulose accessibility was mainly due to the hemicellulose removal [20], lignin-hemicellulose phase separation [27], and/or lignin redistribution caused by DAP.

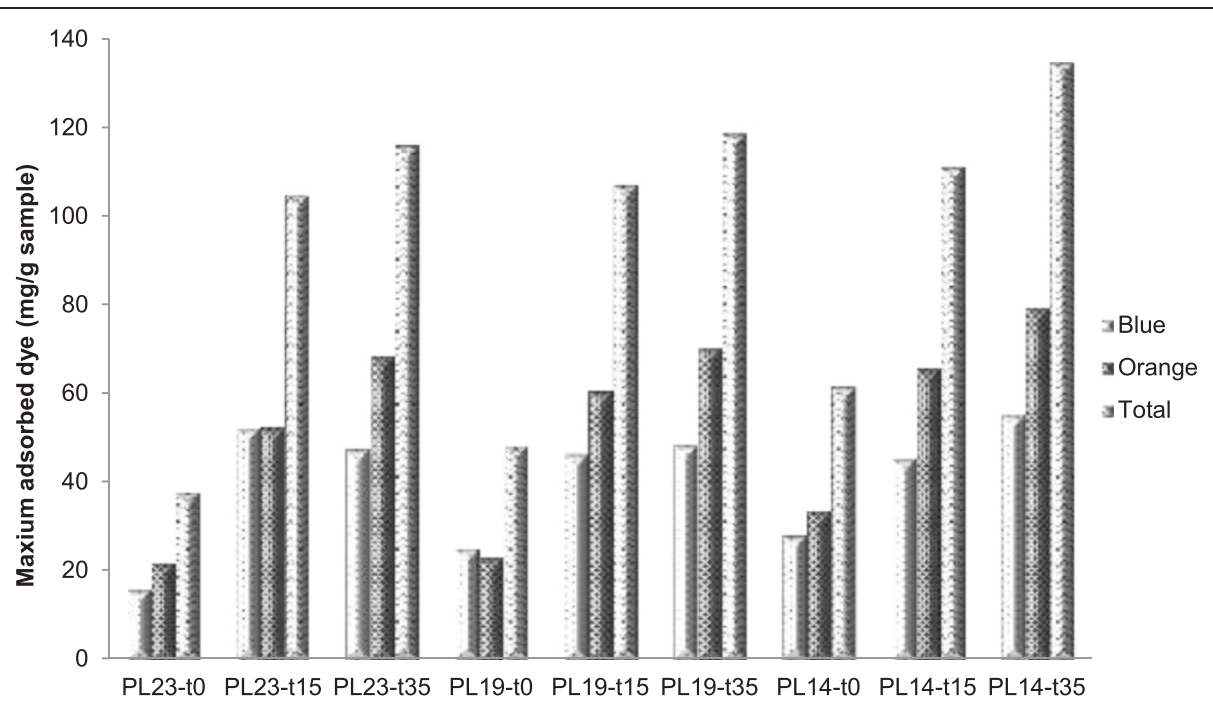

Figure 7 The maximum amount of direct orange 15 dye and direct blue 1 dye adsorbed by untreated and pretreated poplar. Sample code with definition is in Table 1. 


\section{Enzymatic sugar release}

Cellulose ultrastructural changes, measured as a function of pretreatment severity, were evaluated using enzymatic sugar release assays. Sugar yields were calculated through dividing the glucose contents in enzymatic hydrolysis liquid from native, delignified, and dilute acid pretreated poplar samples by the glucan contents from carbohydrate analysis on those native and treated starting materials. Figure 8 summarizes the glucose yield after enzymatic hydrolysis for the delignified substrate after DAP with respect to the unpretreated sample. DAP on undelignified substrate produced a 60\% sugar yield (PL23-t35), and delignification without DAP also produced a $57.5 \%$ yield (PL14-t0). However, initial delignification followed by a second DAP step dramatically enhanced downstream enzymatic hydrolysis to facilitate sugar yields of approximately $80 \%$ for PL14-t35. In addition, P14-t0 with a lower cellulose accessibility (Figure 7) and higher sugar yield than P23-t15 suggests delignification could contribute more to the extent of enzymatic hydrolysis than DAP, as delignification enhances both enzymes macro-accessibility to cellulose and hemicelluloses, as well as enzymes effectiveness [50].

Enzymatic hydrolysis of cellulosic biomass is restricted by substrate recalcitrant factors and influenced by treatment methods. In combination with the results above, reduction in poplar cellulose DP caused by DAP could increase cellulose chain-reducing ends [51], and short chains with a weak hydrogen-bonding network could make cellulose more amenable to enzymatic deconstruction [52]. The increase of cellulose accessibility to cellulases caused by DAP is mainly due to the expansion of the pore size and volume, and the increase of a specific surface area, which thereby improve cellulases adsorption on cellulose surface $[53,54]$. The inevitable increase of cellulose crystallinity and crystallite size with microfibril coalescence after DAP seems to have a negative effect on enzymatic hydrolysis since crystalline regions reduce the resulting enzymatic degradation of cellulose [16]. However, some changes on cellulose crystalline allomorphic states may be beneficial to enhance the sugar yield in enzymatic hydrolysis, such as the increased proportion of paracrystalline cellulose. It is believed to be located on the surface of crystallites as thin monocellular layers which weaken the crystallites, increase cellulose dissolution and accessibility to reagents, and cause intra-lattice swelling [43]. Furthermore, studies of acidified sodium chlorite treatment on Avicel cellulose with different crystallinities have proved that those minimal changes on crystalline and amorphous cellulose by sodium chlorite had no detectable effect on cellulose digestibility [30], which suggests the major role of sodium chlorite treatment on biomass is removing lignin with intact cellulose left, and thereby enhancing the cellulose digestibility.

Lignin content and distribution had a more pronounced effect on biomass recalcitrance and enzymatic digestibility, especially for poplar [29]. However, complete lignin removal on corn stover by sodium chlorite treatment following DAP has been found to reduce cellulose conversion [30], which was proposed to be attributed to cellulose microfibril aggregation in the absence of lignin and hemicellulose. This was confirmed by our NMR and WAXD analysis that indicated lignin presence played a key role in preventing cellulose crystallites increased propensity to co-crystallize and coalesce during DAP, which therefore suggested partial delignification instead of complete lignin removal could better benefit the sugar yield. Furthermore, partial delignification with hemicelluloses removal during DAP retained cell wall spatial structure without elimination of all lignin spacer, increased specific surface area, reduced its irreversible adsorption to the enzyme [55,56], and, to limited extent, caused the cellulose

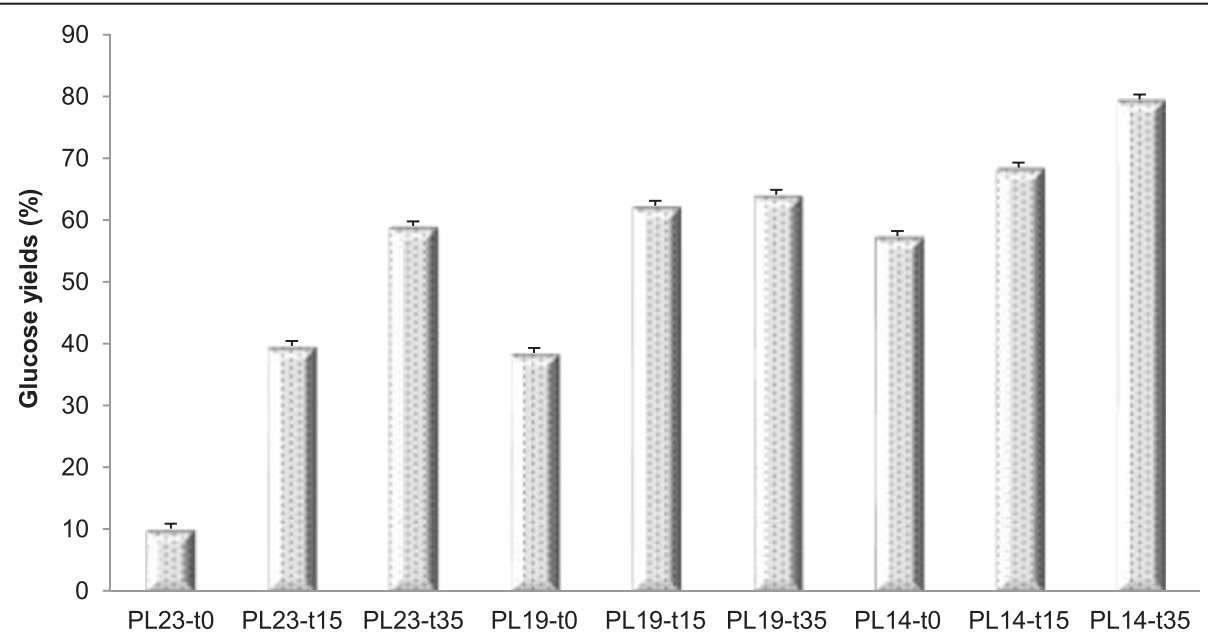

Figure 8 Glucose yields as a result of downscaled enzymatic hydrolysis. Sample code with definition is in Table 1. 
fibril coalescence to provide an optimal pretreated biomass for subsequent enzymatic deconstruction.

\section{Conclusions}

This study is another important step in providing the required data for a comprehensive analysis of biomass in an effort to optimize the integrated operations of pretreatment and enzymatic hydrolysis. In particular, key molecular features related to biomass recalcitrance, specifically cellulose ultrastructure and accessibility were, studied. In the absence of lignin spacer along with hemicellulose removal after DAP, changes occurred to cellulose ultrastructure include increases in cellulose $\%$ crystallinity, cellulose crystallite size, cellulose crystalline transformation, and cellulose accessibility accompanied by a decrease of cellulose DP. NMR and WAXD results indicated that lignin presence played a key role in preventing cellulose crystallite co-crystallization and coalescence during DAP. This indicates lignin acts as a barrier which restricts cellulose crystallinity increase and cellulose crystallite growth, and that partial delignification instead of complete lignin removal is better for enhanced sugar yield.

\section{Materials and methods}

\section{Substrate and enzymes}

Baseline poplar (P. trichocarpa x P. deltoides) samples were harvested between 2007 and 2008 by the National Renewable Energy Laboratory (NREL) at area 0800 at Oak Ridge National Laboratory, Tennessee, United States. Cellulase (Accellerase ${ }^{\mathrm{Tw}}$ 1500, Lot number: 1681198062) and xylanase (Accellerase XY, Lot number: 4901131618) were generously provided by DuPont Industrial Biosciences (Palo Alto, California, United States).

\section{Poplar samples under partial delignification and dilute acid pretreatment}

Poplar samples were size-reduced in a Wiley mill (Thomas Scientific, Swedesboro, NJ , United States) using a 0.250 to $0.177 \mathrm{~mm}$ screen. Extractives were subsequently removed by placing the biomass into an extraction thimble in a Soxhlet extraction apparatus (VWR, West Chester, PA, United States). The extraction flask was filled with 1:2 ethanol:benzene mixture (Sigma-Aldrich (St. Louis, MO, United States) (approximately $150 \mathrm{~mL}$ in total) and then refluxed at a boiling rate which cycled the biomass for at least 24 extractions over a 4 hour period (PL23-t0). Modified acid-chlorite delignification was used to reduce lignin content. Samples were generated by exposure of extracted baseline poplar to $\mathrm{NaClO}_{2}(0.6 \mathrm{~g} / 1.00 \mathrm{~g}$ lignocellulosic dry solids) in acetic acid ( $375 \mathrm{~mL}$ of $0.14 \mathrm{M}$ ) (SigmaAldrich (St. Louis, MO, United States) at $70^{\circ} \mathrm{C}$ for about 15 minutes, followed by a further 30 minutes to generate solids with 19.2 and $14.3 \%$ Klason lignin content (sample labeled as PL19-t0 and PL14-t0, respectively, shown in Table 1). The native sample without any lignin removal and delignified samples with Klason lignin content 19.2 and $14.3 \%$ were subjected to DAP under the same conditions. Poplar samples were transferred to a 4560 mini-Parr $300 \mathrm{ml}$ pressure reactor (Parr Instrument Company, Moline, IL, United States) with $0.1 \mathrm{M} \mathrm{H}_{2} \mathrm{SO}_{4}$ solutions at $5 \%$ dry solids and were then sealed. The impeller speed was set to about $100 \mathrm{rpm}$, and the vessel was heated to $160^{\circ} \mathrm{C}$ for 25 to 30 minutes (at approximately $6^{\circ} \mathrm{C} / \mathrm{min}$ ). The reactor was held at the pretreatment temperature $\pm 2^{\circ} \mathrm{C}$ (approximately 0.65 to $0.69 \mathrm{MPa}$ ) for the specified residence time \pm 30 seconds (15 or 35 minutes). The reactor was then quenched in an ice bath for approximately 5 minutes. The pretreated slurry was filtered to remove the solid material and washed with an excess of deionized filtered water. The pretreated lignocellulosic samples were dried in the fume hood overnight. All yields for biomass recovered after pretreatment ranged between 75 and $85 \%$ by mass. Poplar samples under delignification and DAP at various conditions are summarized in Table 1.

\section{Carbohydrates and Klason lignin analysis}

The extractive-free biomass samples were analyzed according to the NREL standard method for the determination of structural carbohydrates and lignin in biomass [57]. Those polymeric carbohydrates, hydrolyzed into the monomeric forms and soluble in the hydrolysis liquid, were determined by high-performance anion-exchange chromatography with pulsed amperometric detection (HPAEC-PAD) using Dionex ICS-3000 (Dionex Corp., Sunnyvale, CA, United States). Error analysis was conducted by performing carbohydrate and Klason lignin analysis three times on the untreated and pretreated samples, reported as an average with error bars are one standard deviation.

\section{Attenuated total reflectance Fourier transform infrared (ATR-FTIR) spectroscopy analysis of native and pretreated poplar}

To investigate and quantify chemical changes in untreated and pretreated poplar samples with controlled lignin content, a PerkinElmer Spectrum 100 FTIR spectrometer with a universal attenuated total reflectance (ATR) sampling accessory (Perkin-Elmer Inc., Wellesley, MA, United States) was used. Native and pretreated poplar samples were pressed uniformly against the crystal surface via a spring-anvil, and spectra were obtained by 64 scans accumulation from 4,000 to $500 \mathrm{~cm}^{-1}$ at $4 \mathrm{~cm}^{-1}$ resolution. The ATR correction and the baseline correction were carried out orderly by PerkinElmer Spectrum software (Perkin-Elmer Inc., Norwalk, CT, United States) with the equipment. 


\section{Sample preparation for nuclear magnetic resonance spectroscopy}

Isolated cellulose was generated by first isolating holocellulose from milled biomass pulp. Holocellulose was isolated from pretreated samples by exposure to $\mathrm{NaClO}_{2}$ $(1.30 \mathrm{~g} / 1.00 \mathrm{~g}$ lignocellulosic dry solids) in acetic acid (375 $\mathrm{mL}$ of $0.14 \mathrm{M})$ at $70^{\circ} \mathrm{C}$ for 2 hours $[17,58]$. The samples were then collected by filtration and rinsed with an excess of deionized filtered water. This was repeated to ensure complete removal of the lignin component. Isolated cellulose was prepared from the holocellulose sample $(1.00 \mathrm{~g})$ by hydrolysis for 4 hours in $\mathrm{HCl}$ $(100.0 \mathrm{~mL}$ of $2.50 \mathrm{M})$ at $100^{\circ} \mathrm{C}$ as reported by Foston and Ragauskas [17]. The isolated cellulose samples were then collected by filtration and rinsed with an excess of deionized filtered water, and dried in fume hood.

\section{Sample preparation for gel permeation chromatography} Isolated $\alpha$-cellulose was generated by first isolating holocellulose from milled biomass pulp using the method described above. Isolated cellulose was prepared from the holocellulose sample $(1.00 \mathrm{~g})$ by extraction with a $17.5 \%$ $\mathrm{NaOH}$ solution $(50 \mathrm{~mL})$ at $25^{\circ} \mathrm{C}$ for 30 minutes. A total of $50 \mathrm{~mL}$ of deionized filtered water was then added to the $\mathrm{NaOH}$ solution. The extraction was continued with the $8.75 \% \mathrm{NaOH}$ solution $(100 \mathrm{~mL})$ at $25^{\circ} \mathrm{C}$ for an additional 30 minutes. The isolated $\alpha$-cellulose samples were then collected by filtration and rinsed with $50 \mathrm{~mL}$ of $1 \%$ acetic acid, an excess of deionized filtered water, and dried in fume hood.

\section{Nuclear magnetic resonance analysis of cellulose}

The pre-wet NMR samples (with approximately $55 \%$ water content) were prepared with isolated cellulose packed into a 4-mm cylindrical ceramic MAS rotor (Bruker, Billerica, MA, United States). Repetitive steps of packing samples into the rotor were performed to fully compress and load the maximum amount of sample. Solid-state NMR measurements were carried out on a Bruker DSX-400 spectrometer (Bruker, Billerica, MA, United States) operating at frequencies of $100.55 \mathrm{MHz}$ for carbon-13 in a Bruker double-resonance MAS probe head (Bruker, Billerica, MA, United States) at spinning speeds of $10 \mathrm{kHz} . \mathrm{CP} /$ MAS experiments utilized a $5 \mu \mathrm{s}\left(90^{\circ}\right)$ proton pulse, $1.5 \mathrm{~ms}$ contact pulse, 4.0 second recycle delay and 4-8 K scans. All spectra were recorded on wet samples (with approximately $55 \%$ water content), and the line-fitting analysis of spectra was performed using NUTS NMR Data Processing software (Acorn NMR, Inc., Livermore, CA, United States). Error analysis was conducted by performing three individual isolations, NMR acquisitions, and line-fit data processing $[59,60]$.

\section{Gel permeation chromatography analysis of cellulose}

The number-average molecular weight $\left(M_{n}\right)$ and weightaverage molecular weight $\left(M_{w}\right)$ were determined by GPC after tricarbanilation of cellulose. Lignin-free cellulose (15 mg) from each sample was placed in separate test tubes equipped with micro stir bars and dried overnight under vacuum at $40^{\circ} \mathrm{C}$. The test tubes were then capped with rubber septa. Anhydrous pyridine $(4.00 \mathrm{~mL})$ and phenyl isocyanate $(0.50 \mathrm{~mL})$ were added sequentially via syringe. The test tubes were placed in an oil bath at $70^{\circ} \mathrm{C}$ and allowed to stir for 48 hours. Methanol (1.00 mL) was added to quench any remaining phenyl isocyanate. The contents of each test tube were then added drop-wise to a 7:3 methanol:water mixture $(100 \mathrm{~mL})$ to promote precipitation of the cellulose derivative. The solids were collected by filtration and then washed with the methanol: water mixture $(1 \times 50 \mathrm{~mL})$, followed by water $(2 \times 50 \mathrm{~mL})$. The cellulose derivative was then dried overnight under vacuum at $40^{\circ} \mathrm{C}$. Prior to GPC analysis the cellulose derivative was dissolved in tetrahydrofuran $(1.0 \mathrm{mg} / \mathrm{mL})$, filtered through a $0.45 \mu \mathrm{m}$ filter, and placed in a $2 \mathrm{~mL}$ auto-sampler vial.

The molecular weight distributions of the cellulose tricarbanilate samples were then analyzed on an Agilent GPC SEC 1200 system equipped with four Waters Styragel columns (HR1, HR2, HR4, HR6), Agilent refractive index (RI) detector and Agilent ultraviolet detector (Waters, Inc., Milford, MA, United States) $(270 \mathrm{~nm})$ using tetrahydrofuran (THF) as the mobile phase $(1.0 \mathrm{~mL} / \mathrm{min})$ with injection volumes of $20.0 \mu \mathrm{L}$. A calibration curve was constructed based on eight narrow polystyrene standards ranging in molecular weight from $1.5 \times 10^{3}$ to $3.6 \times 10^{6} \mathrm{~g} / \mathrm{mol}$. Data collection and processing were performed using Polymer Standards Service WinGPC Unity software (version 7.2.1, Polymer Standards Service USA, Inc., Warwick, RI, United States). $\mathrm{DP}_{\mathrm{n}}$ and $\mathrm{DP}_{\mathrm{w}}$ were obtained by dividing $\mathrm{M}_{\mathrm{n}}$ and $\mathrm{M}_{\mathrm{w}}$ by $519 \mathrm{~g} / \mathrm{mol}$, the molecular weight of the tricarbanilated cellulose repeat unit. All reported values for molecular weight and DP were the mean average of duplicate samples, except in the case of the untreated material which was the average of six samples for each type of cellulose.

\section{Wide-angle X-ray diffraction analysis of native and pretreated poplar}

WAXD measurements were performed using a thetatheta goniometer PANalytical X'Pert PRO diffractometer (PANalytical in Almelo, Netherlands) with $\mathrm{Cu} K \alpha$ radiation $(\alpha=1.542 \AA)$ operating at $45 \mathrm{kV}$ and $40 \mathrm{~mA}$. Beam divergence on the incident and diffracted beam paths were controlled by the programmable divergence and programmable anti-scatter slits to maintain a constant illuminated spot of $10 \mathrm{~mm}$ on the sample. A fixed $2^{\circ}$ anti-scatter slit and a 10 - $\mathrm{mm}$ wide limiting beam mask 
on the incident beam path; soller slits of 0.04 rad divergence on both beam paths, nickel as a beta-filter, and an X'Celerator scientific detector (PANalytical in Almelo, Netherlands) on the diffracted beam path were the other optic components. The sample, covered with a kapton film to maintain its humidity during measurements, was mounted onto the Spinner PW3064 stage (PANalytical in Almelo, Netherlands) and rotated at $7.5 \mathrm{rpm}$. Data was collected in the continuous scan mode from $5^{\circ}$ to $90^{\circ} 2 \theta$. The width of the diffraction peaks associated with specific reflecting planes $(h k l)$ having a repeat spacing of $d_{h k l}$ was used to estimate the crystallite size, $L_{h k l}$ using the Scherrer equation.

The crystallite size (or dimension) $L_{h k l}$ is calculated by [61,62]:

$$
L_{h k l}=\frac{0.9 \lambda}{\beta_{h k l} \cos \theta}
$$

where $\lambda$ is the X-ray wavelength in $\AA ; \beta_{h k l}$ is the angular full-width at half maximum intensity (FWHM) in radians of the $(h k l)$ line profile; and $\theta$ is the scattering angle. The calculated values of cellulose microfibril crystallite size, $L_{200}$ was obtained from 5 to $30^{\circ} 2 \theta$ range for all samples.

\section{Simons' staining}

DB 1 (Pontamine Fast Sky Blue 6BX) and DO 15 (Pontamine Fast Orange 6RN) dyes were obtained from Pylam Products Co. Inc. (Garden City, New York United States). DB 1 was used as received. Although the original staining method developed by Simons utilized both dyes as received [48], later studies suggested that only the high molecular weight fraction of the DO 15 dye was responsible for the increased affinity for cellulose, whereas the low molecular weight part had a very similar affinity for cellulose as DB 1 [63]. Therefore, an ultrafiltration of DO 15 to remove the low molecular weight part was necessary, and was done by filtering a $1 \%$ (wt/wt) solution of DO 15 through a $100 \mathrm{~K} \mathrm{mem-}$ brane using an Amicon ultrafiltration apparatus (Amicon Inc., Beverly, Massachusetts, United States) under approximately $200 \mathrm{kPa}$ nitrogen gas pressure [64]. To calculate the concentration of the DO 15 after ultrafiltration, $1.00 \mathrm{~mL}$ of the solution was dried in a $50^{\circ} \mathrm{C}$ oven for a week and the weight of the solid residue was measured. Simons' stain was performed according to the modified procedure by Chandra et al. [65]. The amount of dye adsorbed by the biomass sample was determined using the difference between the concentration of the initial added dye and the concentration of the dye in the supernatant calculated by solving two Lambert-Beer law equations simultaneously.

\section{Down-scaled enzymatic sugar release assay}

The high throughput enzymatic hydrolysis method is based on the High Throughput Pretreatment and Enzymatic hydrolysis (HTPH) design at University of California, Riverside (UCR, California, United States). In this particular study, $4.5 \mathrm{mg}$ dry biomass was loaded into individual wells of a custom-built metal well plate by an automation robotics platform (Symyx Technologies, Sunnyvale, California, United States). Then, $446 \mu \mathrm{L}$ deionized water was pipetted into all wells (8-channel pipette, 30 to $300 \mu \mathrm{L}$, Eppendorf, Hamburg, Germany) to achieve a solid loading of $1 \mathrm{wt} \%$. Next, $39 \mu \mathrm{L}$ of a mixture of $1 \mathrm{M}$ citrate buffer ( $\mathrm{pH} 4.8$ ), sodium azide solution and enzymes was pipetted into each well (8 channel pipette, $10-100 \mu \mathrm{L}$, Eppendorf, Hamburg, Germany). The final hydrolysates contained $0.05 \mathrm{M}$ citrate buffer (pH 4.95), and $0.2 \mathrm{~g} / \mathrm{L}$ sodium azide. The resulting enzyme loading corresponded to a high $112.5 \mathrm{mg}$ protein of Accellerase 1500 and $37.5 \mathrm{mg}$ protein of Accellerase ${ }^{\ominus} \mathrm{XY}$ (DuPont Industrial Biosciences, Palo Alto, CA, United States), respectively, per gram of glucan plus xylan in tested biomass. The high protein loading was applied to ensure that the substrate reactivity is not masked by the enzymes ineffectiveness as they can be strongly inhibited by the compounds (such as xylooligomers and phenols) present in the enzymatic hydrolysates. After enzyme addition, the well plate was then clamped between two stainless steel plates with a flat silicone gasket in between. The plate was then placed on its side in an incubation shaker (Multitron Infors-HT, ATR Biotech, Laurel, Maryland, United States) at $50^{\circ} \mathrm{C}$ for 72 hours at $150 \mathrm{rpm}$. Following enzymatic hydrolysis, the well-plate block was allowed to cool to room temperature and then opened. A sealing tape (Nunc, Rochester, New York, United States) was secured to the top of all vials and the entire well plate was centrifuged (CS-6R Centrifuge, Beckman, Fullerton, California, United States) for 20 minutes at $2650 \mathrm{rpm}$. Then, $260 \mu \mathrm{L}$ of the clear hydrolysates solution was transferred to a polypropylene 96-well plate (Agilent, Santa Clara, California, United States) for HPLC analysis. In this part, sugar concentrations were quantified using Agilent 1200 HPLC (Agilent, Santa Clara, California, United States) equipped with an Aminex ${ }^{\text {tn }}$ HPX-87H column (BioRad, Hercules, California, United States) and a refractive index detector. The column heater was set at $65^{\circ} \mathrm{C}$ and the detector was set at $50^{\circ} \mathrm{C}$. The eluent $(5 \mathrm{mM}$ sulfuric acid) was used at a flow rate of $0.6 \mathrm{ml} \mathrm{min}^{-1}$.

\section{Abbreviations}

ATR-FTIR: Attenuated total reflectance Fourier transform infrared spectroscopy; C CP/MAS NMR: ${ }^{13} \mathrm{C}$ cross polarization and magic angle spinning nuclear magnetic resonance; Crl: Crystallinity index; DAP: Dilute acid pretreatment; DB: Direct blue; DO: Direct orange; DP: Degree of polymerization; DP : Numberaverage degree of polymerization; $\mathrm{DP}_{\mathrm{w}}$ : Weight-average degree of polymerization; GPC: Gel permeation chromatography; HPAEC-PAD: Highperformance anion-exchange chromatography with pulsed amperometric detection; HTPH: High throughput pretreatment and enzymatic hydrolysis; 
LCCs: Lignin carbohydrate complexes; LFD: Lateral fibril dimension; LFAD: Lateral fibril aggregate dimension; WAXD: Wide-angle X-ray diffraction.

\section{Competing interests}

The authors declare that they have no competing interests.

\section{Authors' contributions}

QS planned and carried out the poplar delignification, dilute acid pretreatment, NMR, GPC, ATR-FTIR analysis, carbohydrates and Klason Lignin analysis, analyzed the results and wrote the paper. MF participated in the design of the study, helped analyze the results and contributed to the draft of the manuscript. XM carried out the Simons' staining experiment. DS, SVP, HMO and PL participated in wide-angle X-ray diffraction measurement and data analysis. $\mathrm{HL}, \mathrm{CEW}$ and RK participated in the down-scaled enzymatic sugar release analysis and helped revise the manuscript. AJR conceived of the study, and participated in its design and coordination and helped to finalize the manuscript. All authors read and approved the final manuscript for publication.

\section{Acknowledgements}

Hybrid poplar samples were obtained through a collaborative agreement with the Bioenergy Science Center (BESC) located at the Oak Ridge National Laboratory, Oak Ridge, Tennessee (United States). This research is funded by the Genomic Science Program, Office of Biological and Environmental Research, US Department of Energy, under FWP ERKP752 and US Department of Energysponsored BESC. Oak Ridge National Laboratory's Center for Structural Molecular Biology (CSMB) is supported by the Office of Biological and Environmental Research (FWP ERKP291). A portion of this research was also conducted at the Center for Nanophase Materials Sciences, which is sponsored at Oak Ridge National Laboratory by the Scientific User Facilities Division, Office of Basic Energy Sciences, US Department of Energy. QS is grateful for the financial support from the Paper Science \& Engineering (PSE) fellowship program at Renewable Bioproducts Institute (RBI) at the Georgia Institute of Technology (Georgia, United States).

\section{Author details}

'School of Chemistry and Biochemistry, Renewable Bioproducts Institute, Georgia Institute of Technology, 500 10th Street, N.W. Atlanta, GA 30332-0620, USA. ${ }^{2}$ Department of Energy, Environmental and Chemical Engineering, Washington University, 1 Brookings Drive, Saint Louis, MO, 63130, USA. ${ }^{3}$ Center for Structural Molecular Biology and the Biology and Soft Matter Division, Oak Ridge National Laboratory, Oak Ridge, TN, 37831, USA. ${ }^{4}$ Center for Environmental Research and Technology (CE-CERT), Bourns College of Engineering, University of California, 1084 Columbia Avenue, Riverside, CA, 92507, USA. ${ }^{5}$ Department of Chemical and Environmental Engineering, Bourns College of Engineering, University of California, 900 University Avenue, Riverside, CA, 92521, USA. ${ }^{6}$ BioEnergy Science Center (BESC), Oak Ridge National Laboratory (ORNL), Oak Ridge, TN, 37831, USA. ${ }^{7}$ Department of Chemical and Biomolecular Engineering, Department of Forestry, Wildlife, and Fisheries, Center for Renewable Carbon, University of Tennessee, Knoxville, TN 37996-2200, USA.

Received: 17 May 2014 Accepted: 25 September 2014

Published online: 14 October 2014

\section{References}

1. Caffall KH, Mohnen D: The structure, function, and biosynthesis of plant cell wall pectic polysaccharides. Carbohydr Res 2009, 344:1879-1900.

2. Klemm D, Heublein B, Fink HP, Bohn A: Cellulose: fascinating biopolymer and sustainable raw material. Angew Chem Int Ed Engl 2005, 44:3358-3393.

3. $P u Y Q$, Zhang DC, Singh PM, Ragauskas AJ: The new forestry biofuels sector. Biofuels Bioprod Biorefining 2008, 2:58-73.

4. Murphy JD, McCarthy K: Ethanol production from energy crops and wastes for use as a transport fuel in Ireland. Appl Energy 2005, 82:148-166.

5. Sannigrahi $P, P u Y$, Ragauskas A: Cellulosic biorefineries - unleashing lignin opportunities. Curr Opin Environ Sustain 2010, 2:383-393.

6. Foston M, Ragauskas AJ: Biomass characterization: recent progress in understanding biomass recalcitrance. Ind Biotechnol 2012, 8:191-208.

7. Himmel ME, Ding SY, Johnson DK, Adney WS, Nimlos MR, Brady JW, Foust TD: Biomass recalcitrance: engineering plants and enzymes for biofuels production. Science 2007, 315:804-807.
8. Hsu TA, Ladisch MR, Tsao GT: Alcohol from cellulose. Chemtech 1980, 10:315-319.

9. Lacayo $\mathrm{Cl}$, Hwang MS, Ding S-Y, Thelen MP: Lignin depletion enhances the digestibility of cellulose in cultured xylem cells. PLoS One 2013, 8:e68266.

10. Lee SB, Kim IH, Ryu DDY, Taguchi H: Structural-properties of cellulose and cellulase reaction-mechanism. Biotechnol Bioeng 1983, 25:33-51.

11. Puri VP: Effect of crystallinity and degree of polymerization of cellulose on enzymatic saccharification. Biotechnol Bioeng 1984, 26:1219-1222.

12. Fan LT, Lee $Y H$, Beardmore DH: Mechanism of the enzymatic-hydrolysis of cellulose - effects of major structural features of cellulose on enzymatichydrolysis. Biotechnol Bioeng 1980, 22:177-199.

13. Mansfield SD, Mooney C, Saddler JN: Substrate and enzyme characteristics that limit cellulose hydrolysis. Biotechnol Prog 1999, 15:804-816.

14. Yang B, Dai Z, Ding S-Y, Wyman CE: Enzymatic hydrolysis of cellulosic biomass. Biofuels 2011, 2:421-450

15. Del Rio LF, Chandra RP, Saddler JN: Fibre size does not appear to influence the ease of enzymatic hydrolysis of organosolv-pretreated softwoods. Bioresour Technol 2012, 107:235-242.

16. Hall M, Bansal P, Lee JH, Realff MJ, Bommarius AS: Cellulose crystallinity - a key predictor of the enzymatic hydrolysis rate. FEBS J 2010, 277:1571-1582.

17. Foston M, Ragauskas AJ: Changes in lignocellulosic supramolecular and ultrastructure during dilute acid pretreatment of Populus and switchgrass. Biomass Bioenerg 2010, 34:1885-1895.

18. Pu Y, Hu F, Huang F, Davison BH, Ragauskas AJ: Assessing the molecular structure basis for biomass recalcitrance during dilute acid and hydrothermal pretreatments. Biotechnol Biofuels 2013, 6:1-13.

19. Meng X, Foston M, Leisen J, DeMartini J, Wyman CE, Ragauskas AJ: Determination of porosity of lignocellulosic biomass before and after pretreatment by using Simons' stain and NMR techniques. Bioresour Technol 2013, 144:467-476.

20. Jeoh T, Ishizawa Cl, Davis MF, Himmel ME, Adney WS, Johnson DK: Cellulase digestibility of pretreated biomass is limited by cellulose accessibility. Biotechnol Bioeng 2007, 98:112-122.

21. O'sullivan AC: Cellulose: the structure slowly unravels. Cellulose 1997, 4:173-207.

22. Yamamoto H, Horii F: CPMAS carbon-13 NMR analysis of the crystal transformation induced for Valonia cellulose by annealing at high temperatures. Macromolecules 1993, 26:1313-1317.

23. Yamamoto $H$, Horii $F$, Odani $H$ : Structural changes of native cellulose crystals induced by annealing in aqueous alkaline and acidic solutions at high temperatures. Macromolecules 1989, 22:4130-4132.

24. Horii F, Yamamoto H, Kitamaru R, Tanahashi M, Higuchi T: Transformation of native cellulose crystals induced by saturated steam at high temperatures. Macromolecules 1987, 20:2946-2949.

25. Debzi E, Chanzy H, Sugiyama J, Tekely P, Excoffier G: The la $\rightarrow \mid \beta$ transformation of highly crystalline cellulose by annealing in various mediums. Macromolecules 1991, 24:6816-6822.

26. Rinaldi R, Schuth F: Acid hydrolysis of cellulose as the entry point into biorefinery schemes. ChemSusChem 2009, 2:1096-1107.

27. Langan P, Petridis L, O'Neill HM, Pingali SV, Foston M, Nishiyama Y, Schulz R, Lindner B, Hanson BL, Harton S: Common processes drive the thermochemical pretreatment of lignocellulosic biomass. Green Chem 2014, 16:63-68.

28. Sun Q, Foston M, Sawada D, Pingali SV, O'Neill HM, Li H, Wyman CE, Langan $\mathrm{P}, \mathrm{Pu}$ Y, Ragauskas AJ: Comparison of changes in cellulose ultrastructure during different pretreatments of poplar. Cellulose 2014, 21:2419-2431.

29. DeMartini JD, Pattathil S, Miller JS, Li HJ, Hahn MG, Wyman CE: Investigating plant cell wall components that affect biomass recalcitrance in poplar and switchgrass. Energy Environ Sci 2013, 6:898-909.

30. Ishizawa $\mathrm{Cl}$, Jeoh T, Adney WS, Himmel ME, Johnson DK, Davis MF: Can delignification decrease cellulose digestibility in acid pretreated corn stover? Cellulose 2009, 16:677-686.

31. Sannigrahi P, Kim DH, Jung S, Ragauskas A: Pseudo-lignin and pretreatment chemistry. Energy Environ Sci 2011, 4:1306-1310.

32. Marchessault RH: Applications of infrared spectroscopy to the study of wood polysaccharides. Spectrochim Acta 1962, 18:876.

33. Yin YF, Berglund L, Salmen L: Effect of steam treatment on the properties of wood cell walls. Biomacromolecules 2011, 12:194-202.

34. Kumar R, Mago G, Balan V, Wyman CE: Physical and chemical characterizations of corn stover and poplar solids resulting from leading pretreatment technologies. Bioresour Technol 2009, 100:3948-3962. 
35. He JX, Cui SZ, Wang SY: Preparation and crystalline analysis of high-grade bamboo dissolving pulp for cellulose acetate. J Appl Polym Sci 2008, 107:1029-1038.

36. Zhang J, Siika-aho M, Tenkanen M, Viikari L: The role of acetyl xylan esterase in the solubilization of xylan and enzymatic hydrolysis of wheat straw and giant reed. Biotechnol Biofuels 2011, 4:1-10.

37. Jonsson LJ, Alriksson B, Nilvebrant N-O: Bioconversion of lignocellulose: inhibitors and detoxification. Biotechnol Biofuels 2013, 6:16

38. Sun XF, Xu F, Sun RC, Fowler P, Baird MS: Characteristics of degraded cellulose obtained from steam-exploded wheat straw. Carbohydr Res 2005, 340:97-106.

39. Hubbell CA, Ragauskas AJ: Effect of acid-chlorite delignification on cellulose degree of polymerization. Bioresour Technol 2010, 101:7410-7415.

40. Larsson PT, Hult EL, Wickholm K, Pettersson E, Iversen T: CP/MAS C-13-NMR spectroscopy applied to structure and interaction studies on cellulose I. Solid State Nucl Magn Reson 1999, 15:31-40.

41. Newman RH: Carbon-13 NMR evidence for cocrystallization of cellulose as a mechanism for hornification of bleached kraft pulp. Cellulose 2004, 11:45-52.

42. Lindgren $T$, Edlund $U$, Iversen $T$ : A multivariate characterization of crystal transformations of cellulose. Cellulose 1995, 2:273-288.

43. loelovich M, Leykin A, Figovsky O: Study of cellulose paracrystallinity. Bioresource 2010, 5:1393-1407.

44. Wickholm K, Hult EL, Larsson PT, Iversen T, Lennholm H: Quantification of cellulose forms in complex cellulose materials: a chemometric model. Cellulose 2001, 8:139-148.

45. Wickholm K, Larsson PT, Iversen T: Assignment of non-crystalline forms in cellulose I by CP/MAS C-13 NMR spectroscopy. Carbohydr Res 1998, 312:123-129.

46. Hult EL, Larsson PT, Iversen T: Cellulose fibril aggregation - an inherent property of kraft pulps. Polymer 2001, 42:3309-3314.

47. Sturcova A, His I, Apperley DC, Sugiyama J, Jarvis MC: Structural details of crystalline cellulose from higher plants. Biomacromolecules 2004, 5:1333-1339.

48. Simons FL: A stain for use in the microscopy of beaten fibers. Tappi J 1950, 33:312-314.

49. Arantes $V$, Saddler JN: Cellulose accessibility limits the effectiveness of minimum cellulase loading on the efficient hydrolysis of pretreated lignocellulosic substrates. Biotechnol Biofuels 2011, 4:1-17.

50. Kumar R, Wyman CE: Physical and chemical features of pretreated biomass that influence macro-/micro-accessibility and biological processing. In Aqueous Pretreatment of Plant Biomass for Biological and Chemical Conversion to Fuels and Chemicals. Chichester, West Sussex, United Kingdom: John Wiley \& Sons, Ltd; 2013:281-310.

51. Hallac BB, Sannigrahi P, Pu Y, Ray M, Murphy RJ, Ragauskas AJ: Effect of ethanol organosolv pretreatment on enzymatic hydrolysis of Buddleja davidii stem biomass. Ind Eng Chem Res 2010, 49:1467-1472.

52. Pan XJ, Xie D, Yu RW, Saddler JN: The bioconversion of mountain pine beetle-killed lodgepole pine to fuel ethanol using the organosolv process. Biotechnol Bioeng 2008, 101:39-48.

53. Foston M, Ragauskas AJ: Changes in the structure of the cellulose fiber wall during dilute acid pretreatment in populus studied by $\mathrm{H}-1$ and $\mathrm{H}-2$ NMR. Energy Fuels 2010, 24:5677-5685.

54. Chen W-H, Tu Y-J, Sheen H-K: Disruption of sugarcane bagasse lignocellulosic structure by means of dilute sulfuric acid pretreatment with microwave-assisted heating. Appl Energy 2011, 88:2726-2734.

55. Öhgren K, Bura R, Saddler J, Zacchi G: Effect of hemicellulose and lignin removal on enzymatic hydrolysis of steam pretreated corn stover. Bioresour Technol 2007, 98:2503-2510.

56. Converse A, Ooshima H, Burns D: Kinetics of enzymatic hydrolysis of lignocellulosic materials based on surface area of cellulose accessible to enzyme and enzyme adsorption on lignin and cellulose. Appl Biochem Biotechnol 1990, 24:67-73.

57. Sluiter A, Hames B, Ruiz R, Scarlata C, Sluiter J, Templeton D, Crocker D: Determination of structural carbohydrates and lignin in biomass. In Laboratory Analytical Procedure. 1617 Cole Boulevard, Golden, Colorado: National Renewable Energy Laboratory; 2008:80401-83393.

58. Zhang D, Pu Y, Chai X-S, Naithani V, Jameel H, Ragauskas AJ: Elucidating carboxylic acid profiles for extended oxygen delignification of highkappa softwood kraft pulps. Holzforschung 2006, 60:123-129.
59. Virtanen T, Maunu SL, Tamminen T, Hortfing B, Liitia T: Changes in fiber ultrastructure during various kraft pulping conditions evaluated by $\mathrm{C}-13$ CPMAS NMR spectroscopy. Carbohydr Polym 2008, 73:156-163.

60. Pu YQ, Ziemer C, Ragauskas AJ: CP/MAS C-13 NMR analysis of cellulase treated bleached softwood kraft pulp. Carbohydr Res 2006, 341:591-597.

61. Cullity BD, Stock SR: Elements of X-ray Diffraction. Upper Saddle River, New Jersey: Prentice Hall; 2001.

62. Klug HP, Alexander LE: X-ray diffraction procedures: for polycrystalline and amorphous materials. In X-Ray Diffraction Procedures: for Polycrystalline and Amorphous Materials. 2nd edition. Edited by Klug HP, Alexander LE. New York: Wiley; 1974

63. $Y u$ X, Atalla RH: A staining technique for evaluating the pore structure variations of microcrystalline cellulose powders. Powder Technol 1998, 98:135-138.

64. Esteghlalian AR, Bilodeau M, Mansfield SD, Saddler JN: Do enzymatic hydrolyzability and Simons' stain reflect the changes in the accessibility of lignocellulosic substrates to cellulase enzymes? Biotechnol Prog 2001, 17:1049-1054.

65. Chandra R, Ewanick S, Hsieh C, Saddler JN: The characterization of pretreated lignocellulosic substrates prior to enzymatic hydrolysis, part 1: a modified Simons' staining technique. Biotechnol Prog 2008, 24:1178-1185.

doi:10.1186/s13068-014-0150-6

Cite this article as: Sun et al:: Effect of lignin content on changes occurring in poplar cellulose ultrastructure during dilute acid pretreatment. Biotechnology for Biofuels 2014 7:150.

\section{Submit your next manuscript to BioMed Central and take full advantage of:}

- Convenient online submission

- Thorough peer review

- No space constraints or color figure charges

- Immediate publication on acceptance

- Inclusion in PubMed, CAS, Scopus and Google Scholar

- Research which is freely available for redistribution 